City University of New York (CUNY) CUNY Academic Works

\title{
Brand personality and sexuality levels of luxury advertisements
}

Alyssa Dana Adomaitis

New York City College of Technology

Diana Saiki

Ball State University

\section{How does access to this work benefit you? Let us know!}

More information about this work at: https://academicworks.cuny.edu/ny_pubs/705

Discover additional works at: https://academicworks.cuny.edu

This work is made publicly available by the City University of New York (CUNY).

Contact: AcademicWorks@cuny.edu 


\title{
Brand personality and sexuality levels of luxury advertisements
}

\begin{abstract}
This study examined perceived brand attractiveness of and identification with fashion luxury brands given different levels of sexuality in advertisements. Sex in advertisements has become increasingly more common to generate attention and interest in fashion luxury products with limited research on its influence on the consumer. A sample of 1266 males and females completed a survey on brand attractiveness and identification after examining an advertisement of a luxury fashion product. Participants were assigned an advertisement that featured a same-gendered model at one of four levels of sexuality (fully clothed to nude). The results indicated less sexuality in luxury advertisements was better in generating attractiveness to and identification with the brand. These findings are important to scholars and marketers of luxury brands.
\end{abstract}

Key Words: Advertisements, Brand Attractiveness, Brand Identification, Luxury Fashion, Semiotics, Sexuality

\section{Introduction}

Many consumers pursue the desire to purchase luxury brands to fulfill and define a certain social status. Luxury brands such as Chanel, Gucci, and Prada have been purchased not only for functional features but for the symbolic use. Fashion consumerism is an activity predicated by the belief that a perceived need is an actual need. What causes a fashion consumer to act on this impulse to buy is part of semiotics. Many influences on consumers are artificially created largely by advertisers using their understanding of the effect of semiotics on the individual whom is reading the ad. For an advertisement to be 
successful, it must manipulate the behavior of the buyer of fashion using a complex assessment of cultural codes.

What is advertising? Advertising consists of non-personal visual and aural messages disseminated through paid media for the purpose of achieving one or more objectives (Frey and Halterman, 1970, p. 3). The art of advertising exists because of these objectives. The goals of an advertisement are to increase a company's profits, strengthen the attitudes of customers toward the company, and aim for a good position on dealer's shelves or in the mind of the consumer (1970, p.4). With the intent of having a strong positive position in the consumes' minds and influencing their buying decisions, companies advertise to evoke emotions of desire in consumers that only their product can satisfy. Mentally, this places the product high on the pedestal in the mind of consumers as their needs are "fulfilled."

However, since the need to buy "fashion" is filtered through culture, family, income, cinema, and self-perception, the "reality" is constantly shifting. Semiotics in the advertisement reveals the cultural context when a moment is captured. It alters new words, new needs, new moods, and thus new meanings to buyers searching for a newer "reality." Advertisers create social awareness and class differentiation through distinct advertisements. Ads are meant to target social statuses to which one would belong because of materialistic possessions. Advertisers for these high status, luxury products only associate their brands with high class and the leisure life. This type of life that is created through the medium of ads is a lifestyle which many would like to live and be a part of. Fashion advertising is an illusion of a fantasy lifestyle as well and exits only because of the premise that "clothing makes a person." Life is not always easy, fun, or filled with enjoyment; the way it is pictured on the glossy pages of fashion magazines." The major achievement of advertising is to have created a self-fulfilling image of a public 
welfare as drab, brown-painted and seedy, constantly diminished by the high glamour and vivid sexual satisfactions of consumer living" (Sinclair, 1987, p. 29). A consumer begins to desire the fantasy life of the advertisement and subconsciously desires the product being sold in order to live in this imagined world.

Luxury fashion advertisements incorporate sexuality in advertising to garner attention from the viewer and to enhance luxury status. It is important for luxury brands to reach a culturally diverse audience appealing to both men and women. To understand the effectiveness of luxury advertisements, the purpose of this paper was to examine perceptions of men and women of attractiveness and identification of a luxury fashion brand given degree of sexuality presented in advertisements

\section{Theoretical Framework}

Semiotic theory is the science that studies signs and symbols. According to Kaushik and Sen (1990) "the terms semiology and semiotics are used in relation to structural linguistics and structural anthropology" (p.227). "It is the science of signs and how they work" (Stuart and Fuller, 1991, p.270). Signs convey particular meanings to people within their cultural environment. Semiotic analysis reveals the values of a culture by interpreting tangible and intangible objects. Some cultures value materialistic objects, such as jewelry and clothes, whereas other cultures value non-materialistic objects, such as religion, or tribal dance. It is the people of a culture that give meaning and importance to signs and symbols (Kaushik and Sen, 1990; Mick, 1986). People impose their own values, emotions, and attitudes onto the interpretation of signs.

Charles Sanders Pierce (1857-1913) "is considered the founder of American semiotics" (Stuart and Fuller, 1991, p.270). He is a dominant figure in philosophical semiotics. Pierce developed semiotics into a mathematical equation. Pierce created the 
basic model of semiotics to explain the triadic relationship of the sign, its meaning, and the person who perceives the message, which he named the sign, the object, and the interpretant, respectively (Stuart and Fuller, 1991). According to Fuller and Stuart (1991) the sign, represents an object which stands for something to someone. The object is the message conveyed through the sign and the interpretant is "the mental concept of what is communicated by the user" $(1990$, p. 270). The user is the semiotic analysis is either or both, the sender or the receiver of the message (1990). Perce's model uses a triangle with three (3) labeled-points to explain this three-way relationship. To visualize Peirce's mathematical equation, the sign is at the apex of the triangle and the object and the interpretant are on either sides of its legs.

\section{The Semiotics of Charles Sanders Peirce}

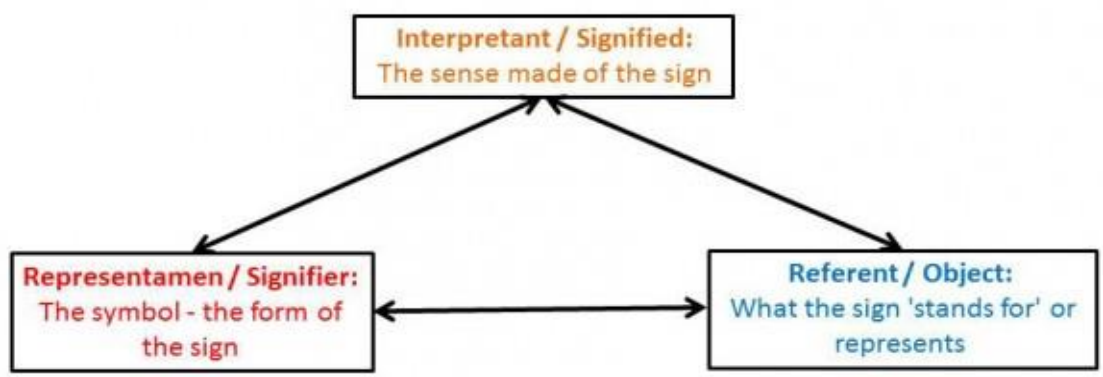

Lesley Lanir

Figure 1: Peirce's elements of meaning.

Bhattacharya and Sen (2017) discuss the underlying conditions that prompt consumers to have an enduring and meaningful relationship with a company. While the examined business to business relationships, their premises can also be applied to the interaction between the ultimate consumer to business. According to Bhattacharya and Sen, meaningful business relationships are formed after the consumer has 
identified with the company. Identification with a company is "active, selective, and volitional on consumers' part and causes them to engage in favorable ....companyrelated behaviors" (p. 77). Within the context of social identity theory (Brewer, 1991; Taijfel and Turner, 1985), when consumers identify with a company, they categorize themselves as a member of the company (Bhattacharya and Sen; Kramer, 1991). Bhattacharya and Sen argue that companies offer social identities to consumers. Identifying with a company is a result of various company communication channels, including advertising.

Prior to consumer's identification with a company, Bhattacharya and Sen (2017) noted that company attractiveness is important. The authors explained that in order for the consumer to perceive the company as attractive, the message from the company must be perceived as having a similar identity to the consumer, distinctive values, and prestige. A company with a similar identity allows the consumer to process the information better (Dutton, Dukerich, and Harquail, 1994) and to express themselves (Pratt, 1998). Identity distinctiveness allows the consumer to distinguish themselves from others (Tajfel and Turner, 1985). While consumers need to relate with a company, they also have a desire for self-enhancement, which has been associated with prestigious brands (e.g. Dutton, Dukerich and Harquail). In the analysis by Bhattacharya and Sen (2017), prestige referred to the perceptions of high regard. When customers associate prestige with a company they then perceive themselves in high regard.

Bhattacharya and Sen (2017) further identified external influences on perceived company attractiveness including consumer knowledge, clarity of their message/brand, and perceived trustworthiness. With regard to consumer knowledge, it is assumed that positive knowledge of the company (Raju, Lonial and Mangold, 
1995) will result in establishing company attractiveness. A company must also be perceived as having a "signature personality" that is communicated clearly in order for the brand to be perceived as attractive (e.g. Shoda and Mischel, 2000). Finally, perceived trustworthiness in this context relates to positive product evaluations and organizational behavior (e.g. Kramer, 1999). Trustworthiness is influenced by historical experiences, as well as, the reputation of the category of company (Bhattacharya and Sen).

\section{Literature Review}

\section{Social Identity through Purchase of Luxury Brands}

In today's consumer culture, many purchase luxury brands to establish social identity (de Bottom, 2004). Social status is important for a number of consumers to buy branded, designer products because of its symbolic nature. For example, when a woman carries a Chanel or Gucci purse, others who know its value will perceive this woman to be "well to do financially," as these designer bags are retailed at prices in the thousands. Status is very important, as status compared to other individuals, means obtaining a higher position whether it is in appearance, wealth, and/ or intelligence (degrees) (Festinger, 1954; Hyman, 1942). In more recent literature, compensatory consumption theory, documents that individuals purchase symbolic, luxury brands to fulfill any deficits in their abilities, such as in status or in skill level, whether psychological or physical (Rucker and Galinsky, 2013; Dichter, 1960). Consumers may purchase luxury products that they can maintain or use to "create" identities through their symbolic value that are desired in society. Others may acquire luxury, branded items to establish whether one actually belongs to or to demonstrate a desire to be a member of a group. Affiliation to a certain membership through a purchase can create status such as the polo club, yachting club, and other affluent organizations. 
Luxury brands are different from other brands in the superior, high quality products they sell (Thomas, 2007). Researchers have acknowledged consuming luxury products temporarily increases self-esteem, providing symbolic, hedonic, and functional value (Hudders and Pandelaere, 2012). Garcia, Weaver, and Chen (2018) found relationships between selecting friends given luxury product display is complex. When participants were asked to select friends based on a brand, the luxury brand was not selected as often as the mid-level brand. Garcia et al. explained, display of luxury products may signal an uncomfortable difference in social status among friends.

\section{Sexuality in Advertising}

The use of sexuality in advertising is prevalent. Courtney and Whipple (1983) define sexuality in advertising as the use of "nudity, sexual imagery, innuendo, and double entendre...employed as an advertising tool for a wide variety of products" (p. 103). Since 1964, there has been an increase in featuring sex in a wide range of publications (e.g. general interest, men's' and women's magazines) (Nelson and Paek, 2005; Reichert, and Carpenter, 2004; Rohlinger, 2002; Soley and Reid, 1988). Today sexual images are common, labeled as a "fixture" in advertising (Reichert, 2007). Women are the primary target of these sexual images and they are also primarily featured in advertisements in sexual poses with limited clothing (Monk-Turner 35 al, 2008). While researchers have examined sex in advertising as an effective method to attract consumers (Putrevu, 2008; Reichert, Heckler, and Jackson, 2001). Researchers have not thoroughly examined how sexuality in advertising influences perceived attractiveness and identity with the brand (Reichert, 2002; 2007).

Researchers have used content analysis to document the use of sexual images in fashion advertising directed at both women and men and its increase over time. 
Thompson (2000) analyzed 2,000 fashion advertisements from Gentlemen's

Quarterly and Vogue between 1964 and 199,4 and found the use of sexual attire and nudity of women and men increased. Krassas, Blauwkamp, and Wesselink (2001) analyzed advertisements from Cosmopolitan and Playboy magazines published in 1965, 1975, 1985 and 1995. In Cosmopolitan, both men and women were increasingly depicted as sex objects over time. Reichert and Carpenter (2004) studied advertisements from Playboy and Esquire. They also reported increases in use of sexual dress and in depictions of intimate contact between models. Stankiewiez and Rosselli (2008) analyzed advertisements from popular US magazines. The use of sex was greater in fashion magazines (men's, women's and young women's) than in news, business, or women's non-fashion magazines. Interested in how Western-looking models and Asian-looking models were depicted in fashion magazines, Frith, Cheng, and Shaw (2004) analyzed 1,130 advertisements from fashion and beauty magazines in the US, Singapore, and Taiwan. As compared to Asian models, Western models were featured more frequently in seductive dress and poses to sell clothing. Millard and Grant (2006) conducted a content analysis of 226 photos from Cosmopolitan, Glamour, and Vogue to study ethnicity and sexualization of women in fashion advertising. Black models were portrayed significantly less often in explicitly sexual poses, but were more often presented in submissive poses than white models.

As the use of sexual adult images has been increasing over time, concern has been expressed that it has expanded to include adolescents. Graff, Murnen, and Krause (2013) used content analysis to investigate whether the sexualization of girls had increased between 1971 and 2011 in Seventeen magazines. Seventeen showed increases in the total number of sexualizing characteristics of featured girls including 
use of low-cut shirts, high-heeled shoes, and tight fitting clothing during this 40 year period.

\section{Why is Sex Used in Advertising?}

Researchers interested in the use of sex in advertising have documented that sexual content is used to attract attention, generate interest, and influence behavioral intentions. Specifically, it has been found sex grabs consumer attention (Bello, Pitts, and Etzel, 1983) and that sexual imagery is remembered (Reichert and Alvaro, 2001). However, sexual imagery may actually serve as a distractor from brand information. For example, researchers have found that viewers of advertisements with sexual content have not been successful at recalling the names of the brands featured (Reichert and Alvaro, 2001).

Several researchers have reported that advertisements with sexual content are more interesting than advertisements without it (Reichert and Alvaro, 2001: Reichert, Heckler, and Jackson, 2001). However, nonsexual advertisements are elaborated on to a greater extent than are sexual ones (Reichert, Heckler, and Jackson, 2001) suggesting that viewers are not carefully analyzing the content of sexual advertisements; thus, the content of the brand promise may be missed by the viewer.

Few researchers have directly related the use of sex in advertising directly to behavior. Rather, what has been measured is behavioral intention. Researchers have documented that purchase intentions are tied to moderately explicit sex in advertisements as opposed to explicit advertisements, low sexual content or ads with no sexual content higher (Grazer and Keesling, 1995). 
Luxury brands often advertise with the image of a desired fantasy world of leisure. Sexuality in advertisements of luxury fashion products is often integrated to achieve this desired image (Rucker and Galinsky, 2013; Dichter, 1960). Research has examined consumer relationships with luxury products, noting that purchasing these products enhances self-esteem (Hudders and Pandelaere, 2012). In addition, research has noted sex in advertising draws attention, generates interest, and might influence behavior intentions (e.g., Reichert and Alvaro, 2001). Sex as part of fashion advertising for both men and women has increased since the late $20^{\text {th }}$ century (e.g., Thompson, 2000). When compared to men, these advertisements featured women more often in submissive and sexual positions (e.g., Millard and Grant, 2006). The purpose of this paper was to examine perceptions of men and women of attractiveness and identification with a luxury brand given the degree of sexuality presented in advertisements. Within the context of the previous literature, the following null hypotheses for the study were developed:

Null H1: There will be no differences in perceived attractiveness among males and females of a luxury brand given the degree of sexuality in advertisements.

Null H2: There will be no differences in identifying with a luxury brand among males and females given the degree of sexuality in advertisements.

\section{Methods}

An instrument was made with a stimuli and a set of items representing attractiveness and brand identification. Reichert and Carpenter (2004) identified five levels of sexuality in advertisements, including: i) demure - every day dress; ii) suggestive - partially exposed upper body; iii) partially clad - undergarments only, and; 
iv) nude - naked or the suggestion of being naked. The stimuli were luxury brand advertisements categorized at each of these five levels of sexuality. Researchers initially assessed the levels of nudity in the advertisements. For the pilot, 56 participants categorized two sets of luxury advertisements at each sexuality level and the highest number in each category was selected for the final study. The advertisements had no more than two models. The final survey had the option to view one of eight photographs, four (one at each level of sexuality) for each gender.

The survey had sixteen items to assess on a 5-point Likert scale ( $1=$ strong disagree to 5=strongly agree) on company attractiveness and company identification as suggested by Bhattacharya and Sen (2003). Eight items represented attractiveness to the brand which comprised of brand attractiveness, similarity, distinctiveness, knowledge, coherence, and trustworthiness. Eight items focused on identification with the brand including loyalty to product, trying new products, purchasing expectations, favorable discussion among friends, wearing the brand logo, anticipating generating positive word of mouth messages, encouraging friends to buy the product, and recruiting others to use the company/brand's product.

After the survey was developed, the study was reviewed and approved by the university's Institutional Review Board (\#1092231-2). The sample consisted of participants in survey service Amazon Turk. The survey was available on Amazon Turk for two weeks. The participants completed to the survey items in response to one of the selected advertisements with a model of like gender. IBM SPSS Statistics (Version 20, 2011, SPSS Inc., Chicago) was used to analyze the data which included descriptive statistics and a Two-Way Multivariate Analysis of Variance (MANOVA).

\section{Sample}

\section{Results}


A total of 1266 participants completed the survey. There were 701(55.4\%) female and $565(44.6 \%)$ male participants The participants were educated with the highest number of participants having a Bachelor's degree $(n=520 ; 41.1 \%)$ or some college $(n=236 ; 18.6 \%)$. The majority were employed $(n=707 ; 55.8 \%)$ or self-employed $(\mathrm{n}=232 ; 18.3 \%)$. Income ranged with $21.4 \%(\mathrm{n}=271)$ earning less than $\$ 25,000$ per year, and 35.1\% $(n=444)$ earning between $\$ 25,000$ and $\$ 49,999$. Another $19 \%(n=$ 234 ) earned between $\$ 50,000$ to $\$ 75,999$ and $12.4 \%$ earned $\$ 75,000$ to $\$ 99,999$. While one preferred not to answer, only $32(9.7 \%)$ earned more than $\$ 100,000$. Participants lived in all regions of the United States: Southeast $(n=338 ; 26.7 \%)$, Midwest $(265$; $20.9 \%)$; Northeast $(232 ; 18.3 \%)$, west $(200 ; 15.8 \%)$ and Southwest $(153 ; 12.1 \%)$ (see Table 1).

Table 1: Participant demographics: Education, employment, income, and region.

\begin{tabular}{lrrc}
\hline & Frequency & Percent & Valid Percent \\
\hline No high school degree & 24 & 1.8 & 1.8
\end{tabular}




\begin{tabular}{lrrr} 
High school or GED & 117 & 9.2 & 9.3 \\
Some college credit & 236 & 18.6 & 18.7 \\
Trade school & 24 & 1.9 & 1.9 \\
Associate degree & 109 & 8.6 & 8.6 \\
Bachelor's degree & 520 & 41.1 & 41.1 \\
Master's degree & 198 & 15.6 & 15.7 \\
Professional degree & 20 & 1.6 & 1.6 \\
Doctorate degree & 16 & 1.3 & 1.3 \\
I prefer not to answer & 2 & .2 & \\
\hline Employed for wages & 707 & 55.8 & 56.3 \\
Self-employed & 232 & 18.3 & 18.5 \\
Out of work, but looking & 47 & 3.7 & 3.7 \\
Out of work/not looking & 18 & 1.4 & 1.4 \\
A homemaker & 84 & 6.6 & 6.7 \\
A student & 85 & 6.7 & 6.8 \\
Military & 14 & 1.1 & 1.1 \\
Retired & 48 & 3.8 & 3.8 \\
Unable to work & 20 & 1.6 & 1.6 \\
I prefer not to answer & 11 & .9 & \\
\hline Less than $\$ 25,000$ & 271 & 21.4 & 22.0 \\
\$25,000 to \$34,999 & 204 & 16.1 & 16.5 \\
\$35,000 to \$49,999 & 240 & 19.0 & 19.4 \\
\$50,000 to \$74,999 & 234 & 18.5 & 19.0 \\
\$75,000 to \$99,999 & 153 & 12.1 & 12.4 \\
\$100,000 to \$149,999 & 91 & 7.2 & 7.4 \\
\$150,000 or more & 41 & 3.2 & 3.3 \\
I prefer not to answer & 32 & 2.5 & \\
\hline Midwest & 265 & 20.9 & 20.9 \\
Northeast & 232 & 18.3 & 18.3 \\
Southeast & 338 & 26.7 & 26.7 \\
Southwest & 153 & 12.1 & 12.1 \\
West & 200 & 15.8 & 15.8 \\
International & 78 & 6.2 & 6.2 \\
\hline
\end{tabular}

Most of the participants were either married $(n=592 ; 46.9 \%)$ or single $(n=552 ; 43.8 \%)$.

The group was mostly Caucasian $(\mathrm{n}=791 ; 62.8 \%)$, with the second highest ethnicity identified as Asian/Pacific Islander ( $\mathrm{n}=209 ; 16.6 \%$ ). Most identified themselves as heterosexual $(\mathrm{n}=996 ; 80.9 \%)$. There were 701(55.4\%) female and $565(44.6 \%)$ male participants (see Table 2).

Table 2: Participant demographics: marital status, ethnicity, sexual orientation and gender. 


\begin{tabular}{lrrr}
\hline Single, never married & 552 & 43.6 & 43.8 \\
Married or partner & 592 & 46.8 & 46.9 \\
Widowed & 21 & 1.7 & 1.7 \\
Divorced & 67 & 5.3 & 5.3 \\
Separated & 29 & 2.3 & 2.3 \\
I Prefer not to answer & 5 & .4 & \\
\hline White & 791 & 62.5 & 62.8 \\
Hispanic or Latino & 71 & 5.6 & 5.6 \\
Black or African American & 113 & 8.9 & 9.0 \\
Native American & 45 & 3.6 & 3.6 \\
Asian / Pacific Islander & 209 & 16.5 & 16.6 \\
Other & 30 & 2.4 & 2.4 \\
I prefer not to answer & 7 & 7 & .6 \\
\hline Heterosexual & 996 & 78.7 & 80.9 \\
Homosexual & 79 & 6.2 & 6.4 \\
Bisexual & 139 & 11.0 & 11.3 \\
Other & 17 & 1.3 & 1.4 \\
I prefer not to answer & 35 & 2.8 & \\
\hline Female & 701 & 55.4 & 55.4 \\
Male & 565 & 44.6 & 44.6 \\
Total & 1266 & 100.0 & 100.0 \\
\hline
\end{tabular}

\section{Perceived Attractiveness}

Overall, the Demure advertisement was perceived has having the highest

Company Attractiveness $(m=3.21)$ and the Nude advertisement had the least $(m=2.81)$.

Males perceived the Demure luxury advertisement with the highest Company

Attractiveness $(\mathrm{m}=3.37)$ and the Nude photograph had the lowest Company

Attractiveness mean $(m=2.84)$. Females perceived the Demure $(m=3.09)$ and Suggestive $(m=3.10)$ as attractive. Similar to the males, females perceived the Nude luxury advertisement as least attractive $(\mathrm{m}=2.79)$ (see Table 3). 
Table 3: Mean scores of company attractiveness: females, males, and total sample.

\begin{tabular}{|c|c|c|c|c|}
\hline Gender & Condition & Mean & $\begin{array}{l}\text { Std. } \\
\text { Dev. }\end{array}$ & $\mathrm{N}$ \\
\hline \multirow[t]{5}{*}{ Female } & Demure & 3.09 & .72 & 177 \\
\hline & Suggestive & 3.10 & .75 & 176 \\
\hline & Partial Clad & 2.91 & .71 & 177 \\
\hline & Nude & 2.79 & .85 & 171 \\
\hline & Total & 2.97 & .77 & 701 \\
\hline \multirow[t]{5}{*}{ Male } & Demure & 3.37 & .69 & 143 \\
\hline & Suggestive & 3.01 & .69 & 141 \\
\hline & Partial Clad & 3.06 & .82 & 142 \\
\hline & Nude & 2.84 & .76 & 139 \\
\hline & Total & 3.07 & .76 & 565 \\
\hline \multirow[t]{5}{*}{ Total } & Demure & 3.21 & .72 & 320 \\
\hline & Suggestive & 3.06 & .72 & 317 \\
\hline & Partial Clad & 2.98 & .76 & 319 \\
\hline & Nude & 2.81 & .81 & 310 \\
\hline & Total & 3.02 & .77 & 1266 \\
\hline
\end{tabular}

Null H1: There will be no differences in perceived attractiveness among males and females of a luxury brand given the degree of sexuality in advertisements.

The pairwise comparisons demonstrated statistically significant differences in Company Attractiveness ratings (mean dif. $=-0.10, \mathrm{SE}=0.04,=.019$ ). Among females Company Attractiveness ratings were: Demure (Mean/SD 3.09 $\pm 0.72, \mathrm{n}=177$ ), Suggestive (Mean/SD 3.10 $\pm 0.75, \mathrm{n}=176)$, Partially Clad (Mean/SD $2.91 \pm 0.71$, $\mathrm{n}=177)$, and Nude (Mean/SD $2.79 \pm 0.85, \mathrm{n}=171)$. For females, Demure there was a statistically significant higher mean when compared to Partially Clad (mean dif. $=.177$, 
$\mathrm{SE}=0.080,=.026)$ and Nude (mean dif. $=.297, \mathrm{SE}=0.81, \leq .001)$. In addition,

Suggestive was perceived as more attractive producing a statistically significant to

Partially Clad (mean dif. $=.193, \mathrm{SE}=0.080,=.026)$ and Nude (mean dif. $=.312, \mathrm{SE}$ $=0.81, \leq .001)$ (see Figure 2).

Among males the Company Attractiveness ratings were as follows: Demure (Mean/SD $3.37 \pm 0.69, \mathrm{n}=143)$, Suggestive (Mean/SD $3.01 \pm 0.69, \mathrm{n}=141)$, Partially Clad (Mean/SD $3.06 \pm 0.82, n=142)$, and Nude (Mean/SD $2.84 \pm 0.76, n=139)$. For men, all of the levels of sexuality had a statistically significant relationship to Demure, with the Demure image seen as more Attractive (Demure to Suggestive, mean dif. $=$ $.366, \mathrm{SE}=0.89, \leq .001 ;$ Demure to Partially Clad, mean dif. $=.309, \mathrm{SE}=0.089,=.0001$; Demure to Nude, mean dif. $=.534, \mathrm{SE}=0.089, \leq .001)$. In addition, with regards to Company Attractiveness responses among males, Partially Clad image had a statistically significant relationship to Nude, mean dif. $=.225, \mathrm{SE}=0.090,=.012$ ) (see Figure 2).

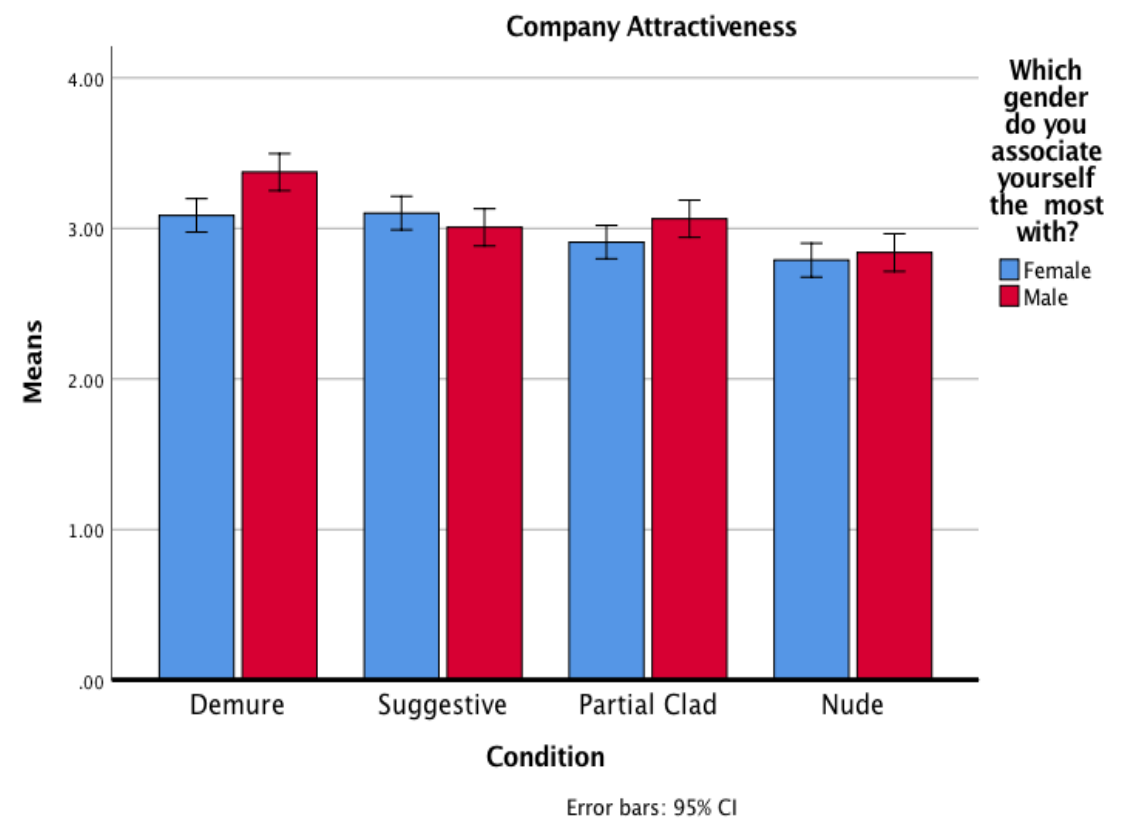

Figure 2. Company attractiveness means. 


\section{Brand Identification}

As far as identification with the brand/company was concerned, the Demure advertisement had the highest mean for both females $(\mathrm{m}=2.62)$ and males $(\mathrm{m}=2.93)$. Females and males mildly disagreed with these statements related to company identification (see Table 4).

Table 4: Mean scores of company identification: females, males, and total sample.

\begin{tabular}{llccc}
\hline Gender & Condition & Mean & $\begin{array}{c}\text { Std. } \\
\text { Deviation }\end{array}$ & $\mathrm{N}$ \\
\hline Female & Demure & 2.62 & 1.02 & 177 \\
& Suggestive & 2.60 & 1.11 & 176 \\
& Partial Clad & 2.46 & .99 & 177 \\
& Nude & 2.30 & 1.10 & 171 \\
\cline { 2 - 5 } & Total & 2.50 & 1.06 & 701 \\
\hline Male & Demure & 2.93 & 1.00 & 143 \\
& Suggestive & 2.52 & 1.03 & 141 \\
& Partial Clad & 2.60 & 1.18 & 142 \\
& Nude & 2.58 & .99 & 139 \\
\cline { 2 - 5 } & Total & 2.66 & 1.06 & 565 \\
\hline Total & Demure & 2.76 & 1.02 & 320 \\
& Suggestive & 2.56 & 1.08 & 317 \\
& Partial Clad & 2.53 & 1.08 & 319 \\
& Nude & 2.42 & 1.06 & 310 \\
\cline { 2 - 4 } & Total & 2.57 & 1.06 & 1266 \\
\hline
\end{tabular}




\section{and females given the degree of sexuality in advertisements.}

As noted above, the multivariate was significant for identifying with the company when considered with aesthetics of the company to levels of sexuality. Comparisons on the items to test identifying with the company resulted in statistically significant differences between males and females and levels of identifying with the company $F(1,1258)=7.55, p=.006$. Levels of sexuality and identifying with the company had statistically significant relationships in company attractiveness $F$ (3, $1258)=5.73, p=.001$. When considering both the level of sexuality in the advertisement and gender the relationships were not significant, $F(3,1258)=3.64, p=.095$ (see Table $3)$.

The mean scores for Company Identification were: Demure (Mean/SD $2.76 \pm$ $1.02, \mathrm{~N}=320$ ), Suggestive (Mean/SD $2.56 \pm 1.08, \mathrm{~N}=317$ ), Partially Clad (Mean/SD $2.53 \pm 1.08, \mathrm{~N}=319)$, and Nude (Mean/SD $2.42 \pm 1.06, \mathrm{n}=310)$. Demure had statistically significant relationships with all of the other levels of sexuality including: Suggestive (Mean dif. $=0.22, \mathrm{SE}=.08, \mathrm{p}=.010)$, Partially Clad (Mean dif. $=0.24, \mathrm{SE}=.08, \mathrm{p}=$ .013 ), and Nude (Mean dif. $=0.34, \mathrm{SE}=.08, \mathrm{p} \leq .001)$.

The pairwise comparisons of gender demonstrated statistically significant differences Company Identification ratings (mean dif. $=-0.16, \mathrm{SE}=0.06,=.006$ ). Female Mean scores of Company Identification for each advertisement were as follows: Demure $($ Mean/SD $2.62 \pm 1.02, \mathrm{n}=177)$, Suggestive $($ Mean/SD $2.60 \pm 1.11, \mathrm{n}=176)$, Partially Clad (Mean/SD $2.46 \pm 0.99, \mathrm{n}=177$ ), and Nude (Mean/SD $2.30 \pm 1.10, \mathrm{n}=171$ ). Only the relationship between Demure and Nude were statistically significant (Mean dif. $=0.325, \mathrm{SE}=.113, \mathrm{p}=.008)$, with participants identifying with the company featuring in their advertisement the Demure more than the Nude level of sexuality. Mean scores of Company Identification for males given each advertisement were as follows: Demure 
$($ Mean/SD $2.93 \pm 1.00, \mathrm{n}=143)$, Suggestive $($ Mean/SD $2.52 \pm 1.03, \mathrm{n}=141)$, Partially

Clad (Mean/SD $2.60 \pm 1.18, \mathrm{n}=142)$, and Nude (Mean/SD $2.58 \pm 0.99, \mathrm{n}=139)$.

Statistically significant differences were found between Demure and the other levels of sexuality features in the advertisements (Suggestive, Mean dif. $=0.406, \mathrm{SE}=.125, \mathrm{p}=$ .001 ; Partially Clad Mean dif. $=0.326, \mathrm{SE}=.125, \mathrm{p}=.009$, and Nude, Mean dif. $=$ $0.352, \mathrm{SE}=.126, \mathrm{p}=.005)($ see Figure 3$)$.

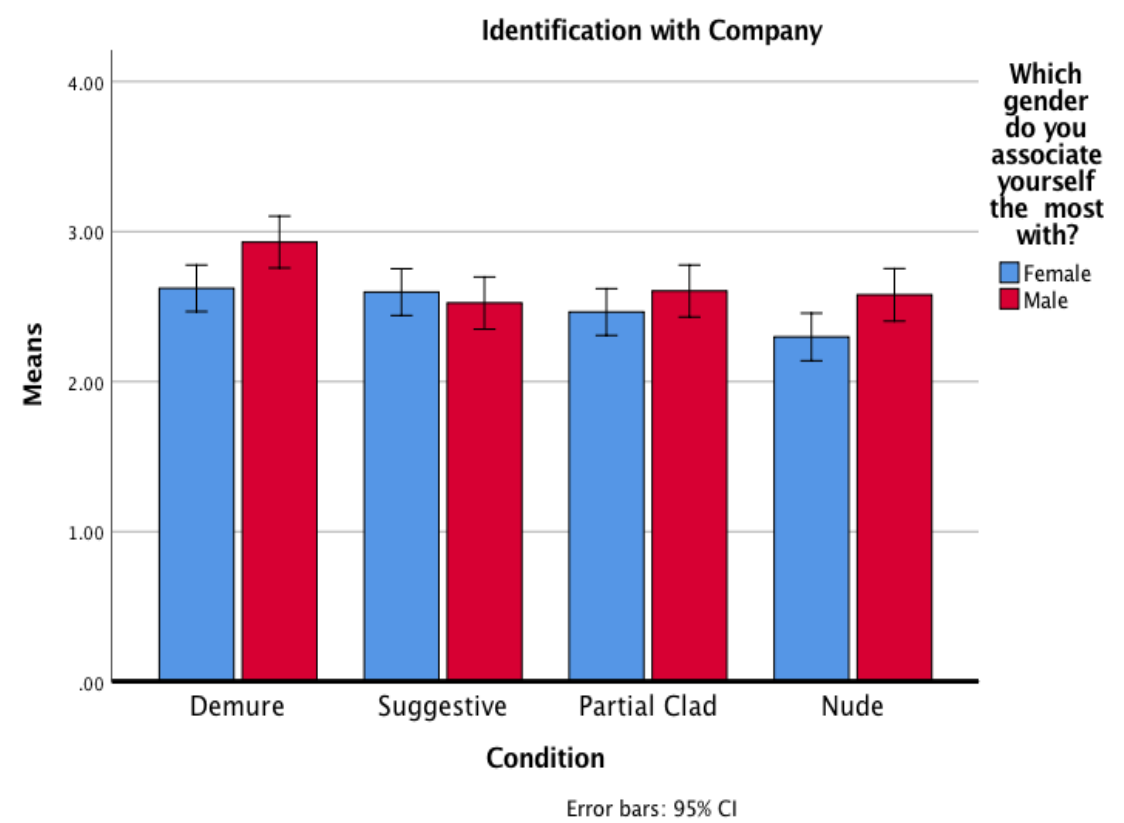

Figure 3: Mean scores of identification with the company.

\section{Discussion}

Luxury fashion brands promote a high status lifestyle through their advertisements often featuring sexuality to gain attention and interest. According to symbolic interaction theory, there is a triadic relationship in making meanings of objects including the sign or object, its meaning, and the person who perceives the sign. This study supports this general theory because the meanings of the advertisements varied 
given different levels of sexuality. In addition, men and women varied in their perceptions of the advertisements. Furthermore, Bhattacharya and Sen (2017) specify that in order to influence consumer behavior, the brand/company must be perceived as attractive and it has to be a company the consumer identifies with. Within this framework, it may be assumed that advertisements with the least sexuality will prompt a better connection with consumers than advertisements with greater sexuality. Both men and women perceived the images as attractive, particularly with less nudity and they identified with the company with the least sexuality (Demure). These results were particularly true for females, who identified with the company decreased in sequence as level of sexuality increased.

The results also suggest a complex relationship between the consumer perceptions and nudity in advertisements for luxury brands. Sex may garner attention (Bello, Pitts, and Etzel, 1983) and interest (e.g., Heckler, and Jackson, 2001), but as other researchers have found nudity might be a detractor (Reichert and Alvaro, 2001) or the message might be missed due to consumers' lack of careful analyses of the content of sexual advertisements (Reichert, Heckler, and Jackson, 2001). If perceptions of attractiveness and identifying with the brand are associated with behavior (Bhattacharya and Sen, 2017), then these findings contradict research that found higher degree of sexuality in advertisements equates greater intent to purchase (Grazer and Keesling, 1995). Finally, the findings can be interpreted within the context of the increase in the use of sexuality in the last 50 years (e.g. Nelson and Paek, 2005; Reichert and Carpenter, 2004). Perhaps consumers are becoming more accustom to sexually explicit advertising, thus diminishing interest in the perceived attractiveness of and identity with the brand.

\section{Conclusion, Limitations, and Suggestions for Further Research}


This study is unique in that: i) it examines consumer perceptions of different levels of sexuality featured in luxury brand advertisements; ii) it examines perceived attractiveness of a luxury brand given different levels of sexuality; iii) it examines brand identification given varying levels of sexuality featured in luxury advertisements, and iv) the survey is original in its use of Bhattacharya and Sen's (2017) concepts for consumer and business rather than business to business relationship. The findings are useful for marketing luxury brands. Given these findings, it is suggested that luxury advertisers limit the use of sexuality to better relate with the consumer, particularly women.

The limitations of the study include; i) the sample was pooled from Amazon Turk, ii) Same gender models were examined by the participants, and iii) the sample mostly resided in the United States. Further study could specifically target audiences that purchase luxury merchandise and broaden the sample to other countries. In addition, the model in the advertisement could vary from the participant's gender or ethnicity. For example, men might have different reactions to the advertisement if a female was modeling the product rather than a man.

\section{References}

Bello, D. C., Pitts, R. E., and Etzel, M. J., 1983. The communication effects of controversial sexual content in television programs and commercials. Journal of Advertising, 12(3), pp.32-42. http://dx.doi.org/10.1080/00913367.1983.10672846

Bhattacharya, C. B. and Sen, S., 2003. Consumer-company identification: A framework for understanding consumers' relationships with companies. Journal of Marketing, 67(2), pp. 76-88.

Brewer, M. B., 1991. The social self: On being the same and different at the same time, Personality and Social Psychological Bulletin, 17(5), pp. 475-482.

Courtney, A. E. and Whipple, T. W., 1983. Sex stereotyping in advertising. Lexington, 
MA: Lexington Books.

de Bottom, A., 2004. Status anxiety. London: Penguin Books Publishing.

Dichter, E., 1960. Strategy of desire. New York: Doubleday Publishing.

Dutton, J. E., Dukerich, J. M., and Harquail, C. V., 1994. Organizational images and member identification. Administrative Science Quarterly, 39(34), pp. 239-63.

Festinger, L. (1954). A theory of social comparison processes. Human Relations. 7(2), 117-140.

Frey, A. W. and Halterman, J. C., 1970. Advertising. Fourth ed. New York: The Ronald Press Company.

Frith, K., Cheng, H., and Shaw, P., 2004. 'Race and beauty': A comparison of Asian and Western models in women's magazine advertisements. Sex Roles, 50(1/2), pp. 53-61.

Garcia, S. M., Weaver, K., and Chen, P. (2018). The status signal paradox. Social Psychology and Personality Sciences. doi: https://doi.org/10.1177/1948550618783712

Graff, K. A., Murnen, S. K., and Krause, A. K., 2013. Low-cut shirts and high-heeled shoes: Increased sexualization across time in magazine depictions of girls. Sex Roles, 69, pp.571-582. doi: 10.1007/s11199-013-0321-0

Grazer, W., and Keesling, G., 1995. The effect of print advertising's use of sexual themes on brand recall and purchase intention: A product specific investigation of male responses. Journal of Applied Business Research, 11, 47-58.

Hudders, L., and Pandelaere, M. 2012. Indulging the self positive consequences of luxury consumption. In: K.P. Wiedmann, N. Hennigs, eds. 2012. Luxury marketing. Gabler Verlag: Wiesbaden. pp. 119-137. 
Hyman, H. H., 1942. The psychology of status. New York: Columbia University Press.

Kaushik, M., and Sen, A., 1990. Semiotics and qualitative research. Journal of the Market Research Society, 32(2), pp. 227-242.

Kramer, R. M., 1991. Intergroup relationships and organizational dilemmas: The role of categorization processes. Research in Organizational Behavior, 13, pp. 191-207.

Kramer, R. M., 1999. Trust and distrust in organizations: Emerging perspectives, enduring questions. Annual Review of Psychology, 50, pp. 569-598.

Krassas, N. R., Blauwkamp, J.M., a n d Wesselink, P, 2001. Boxing Helena and Corseting Eunice: Sexual rhetoric in Cosmopolitan and Playboy Magazines. Sex Roles, 44(11), p. 12.

Mick, D., 1986. Consumer research and semiotics: Exploring the morphology of signs, symbols, and significance. Journal of Consumer Research. 13, pp. 196-213. $10.1086 / 209060$.

Millard, J. and R. Grant, P., 2006. The stereotypes of black and white women in fashion magazine photographs: The pose of the model and the impression she creates. Sex Roles. 54. 659-673. 10.1007/s11199-006-9032-0.graff

Monk-Turner, E., Wren. K., McGill, L., Matthiae, C., Matthiae, C., Brown, S., and Brooks, D., 2008. Who is gazing at whom? A look at how sex is used in magazine advertisements. Journal of Gender Studies, 17(3), pp. 201-209.

Nelson, M. R., and Paek,H-J., 2005. Cross-cultural differences in sexual advertising content in a transnational women's magazine. Sex Roles, 53, pp. 371-383.

Pratt, M. G., (1998). To be or not to be: Central questions in organizational identification. In Identity in Organizations: Building theory through 
conversations, D. A. Whetten and P. C. Godfrey, eds. Thousand Oaks, CA: Sage Publications, pp.171-207.

Putrevu, S., 2008. Consumer responses toward sexual and nonsexual appeals: The influence of involvement, need for cognition (NFC), and gender. Journal of Advertising, 37(2), pp. 57-70, DOI:10.2753/JOA0091-3367370205

Raju, P. S., Lonial, S. C., and Mangold, G., 1995. Differential effects of subjective knowledge, objective knowledge, and usage experience on decision making: An exploratory investigation. Journal of Consumer Psychology, 4(2), pp. 153-80.

Reichert, T., 2007. Does sex in advertising work?: A review of scholarly research informed by professional opinion. Advertising and Society Review, 8(2). Retrieved from https://muse.jhu.edu/journals/advertising_and_society_review/v008/8.2 reichert.html

Reichert, T., 2002. Sex in advertising research: A review of content, effects, and functions of sexual information in consumer advertising. Annual review of sex research, 13(1), pp. 241-274.

Reichert, T., and Alvaro, E., 2001. The effects of sexual information on ad and brand processing and recall.Southwestern Mass Communication Journal 17(1), pp. $9-17$.

Reichert, T., and Carpenter, C. 2004. An update on sex in magazine advertising: 1983 to 2003. Journalism and Mass Communication Quarterly, 8, pp. 823-837.

Reichert, T., Heckler, S., and Jackson, S. 2001. The effects of sexual social marketing appeals on cognitive processing and persuasion. Journal of Advertising, 30, pp. 13-27.

Reichert, T., and Ramirez, A. 2000. Defining sexually oriented appeals in advertising: 
A grounded theory investigation. Advances in Consumer Research, 27, pp. 267273.

Rohlinger, D. A., 2002. Eroticizing men: Cultural influences on advertising and male objectification. Sex Roles, 46, pp. 61-74.

Rucker, D. D., and Galinsky, A. D., 2013. Compensatory consumption. In A. A. Ruvio, and R. W. Belk, Eds. 2013, The Routledge companion to identity and consumption. New York: Routledge. pp. 156-174.

Shoda, Y. and Mischel, W., 2000. Reconciling contextualize and the core assumptions of personality psychology. European Journal of Personality, 14(4), pp. 407-428.

Sinclair, J., 1987. Images incorporated: Advertising as industry and ideology. London: Croom Helm Publishing.

Soley, L. C., and Reid, L. N., 1988. Taking it off: Are models in magazine ads wearing less? Journalism Quarterly, 65, 960-966.

Stankiewicz, J. M., and Rosselli, F., 2008. Women as sex objects and victims in print advertisements. Sex Roles: A Journal of Research, 58(7-8), pp. 579-589.

Stuart, E. W. and Fuller, B. K., 1991. Clothing as communication in two business-tobusiness sales settings, Journal of Business Research, 23 (3), pp. 269-290.

Tajfel, H. and Turner, J. C., 1985, The social identity theory of intergroup behavior. In Psychology of intergroup relations. S. Worchel and W. G. Austin, eds. Chicago: Nelson- Hall, pp. 6-24.

Thomas, D., 2007. Deluxe: How luxury lost its luster. New York: Penguin Group Thompson, M. J., 2000. Gender in magazine advertising: Skins sells best. Clothing and Textiles Research Journal, 18(3), pp. 178-181. https://doi.org/10.1177/0887302X0001800306 
